\title{
CASE STUDY OF THE LIFE CYCLE ASSESSMENT OF A VENTILATED FAÇADE IN A CERTAIN CLIMATIC ZONE OF SPAIN IN A POSTGRADUATE COURSE
}

\author{
N. Ata-Ali, J.V. Martí, V. Yepes, J.J. Pons \\ ICITECH. Dept. Ingeniería de la Construcción y Proyectos de Ingeniería Civil. Universitat \\ Politècnica de València (SPAIN)
}

\begin{abstract}
This paper deals with a case study aimed for students of the "Advanced Methods and Technology in Construction" subject, taught in the Master's Degree in Planning and Management in Civil Engineering (MUPGIC) of the Universitat Politècnica de València. In this course advanced construction procedures are taught. This article presents the case study of a ventilated façade, which has a constructive system that makes it aesthetically attractive and energetically efficient. The case study, for the students, consists in the life cycle assessment of a certain ventilated façade type in two different climatic zones of Spain: Valencia and Ávila, using the Ecoinvent database. Students must take into account that both cities have a very different climate and make the decision to change some of the constructive elements depending on the results. Students will learn to understand and apply advanced constructive procedures. Furthermore, they will acquire transversal competencies such as the decision-making, and problem analysis, and solving capacities, considering the ethical, environmental and professional responsibilities. This article is the preamble for future studies related to the life cycle assessment of a construction or unit from it, considering both an economic and energetic point of view as well as an economic and social one.
\end{abstract}

Keywords: engineering training, postgraduate course, applied research, sustainability, footbridge, lifecycle, environmental impact.

\section{INTRODUCTION}

\subsection{Postgraduate studies in the engineering field}

In recent years, education and training in engineering has undergone a change in Spain and the rest of Europe. To improve the economic development of this sector, students require additional formation to obtain the required knowledge. Masters and Postgraduate courses (MSc) allow students to complement their training and expand their scientific knowledge in order to specialize in a specific field. The Polytechnic University of Valencia offers a large number of these masters and postgraduate courses. One of them, is the Master's Degree in Planning and Management in Civil Engineering (MUPGIC) that delves into the related knowledge in the planning and management of projects, works, infrastructures and companies in the construction sector. The objective is to present a research work related to the topic of "Advanced methods and technologies in work". Our research group has made several articles related to this topic [1-5].

\subsection{Background}

The construction sector in the European Union (EU) has a fundamental role in the economy. It generates almost $10 \%$ of its GDP and provides employment for 20 million people [6]. Construction is one of the main responsible sectors for the consumption of natural resources. Within construction, the housing sector represents an important energy consumption and a great amount of environmental impacts. The EU, to address this sector, has developed a number of regulations $[7,8]$ that focus on reducing energy consumption, taking into account the life cycle of housing, and considering its environmental impacts. To carry out an in-depth study of the use of the energy of a building and its environmental impact, a life cycle analysis (LCA) is required, to know the different impacts that are going to be generated, and thus, to be able to make an improvement to reach a solution as sustainable as possible. LCA, therefore, is a very useful method to help us to make decisions with the purpose of improving the energy efficiency. Wiessenberger and others [9] have shown that LCA has been analyzed in different publications for the last 20 years. 
Other authors [10] also focused on the construction sector and on civil engineering constructions. Nowadays, with the existing bibliography, it is demonstrated that there is a great variety of methodological options to carry out an LCA.

\section{LCA METHOD}

The objective of the study is accomplished with the use of the LCA method. This helps us to calculate the environmental impact caused from the production of each material used in the construction through the use and maintenance of the building and ending with its demolition [11]. Knowing the impact on the environment helps us to make the best choice of materials as well as the best possible constructive section.

\subsection{Goal and scope definition}

When a designer/architect is making a building, he must always think of the best option in terms of materials and constructive solutions, both from the point of view of energy efficiency, and from the economic point of view, without losing the main objective to satisfy the purpose that this building will serve throughout its life cycle (residential, industrial, commercial...).

If we focus on the case study that concerns us, the realization of the enclosure of a single family house, can have several constructive solutions [12].

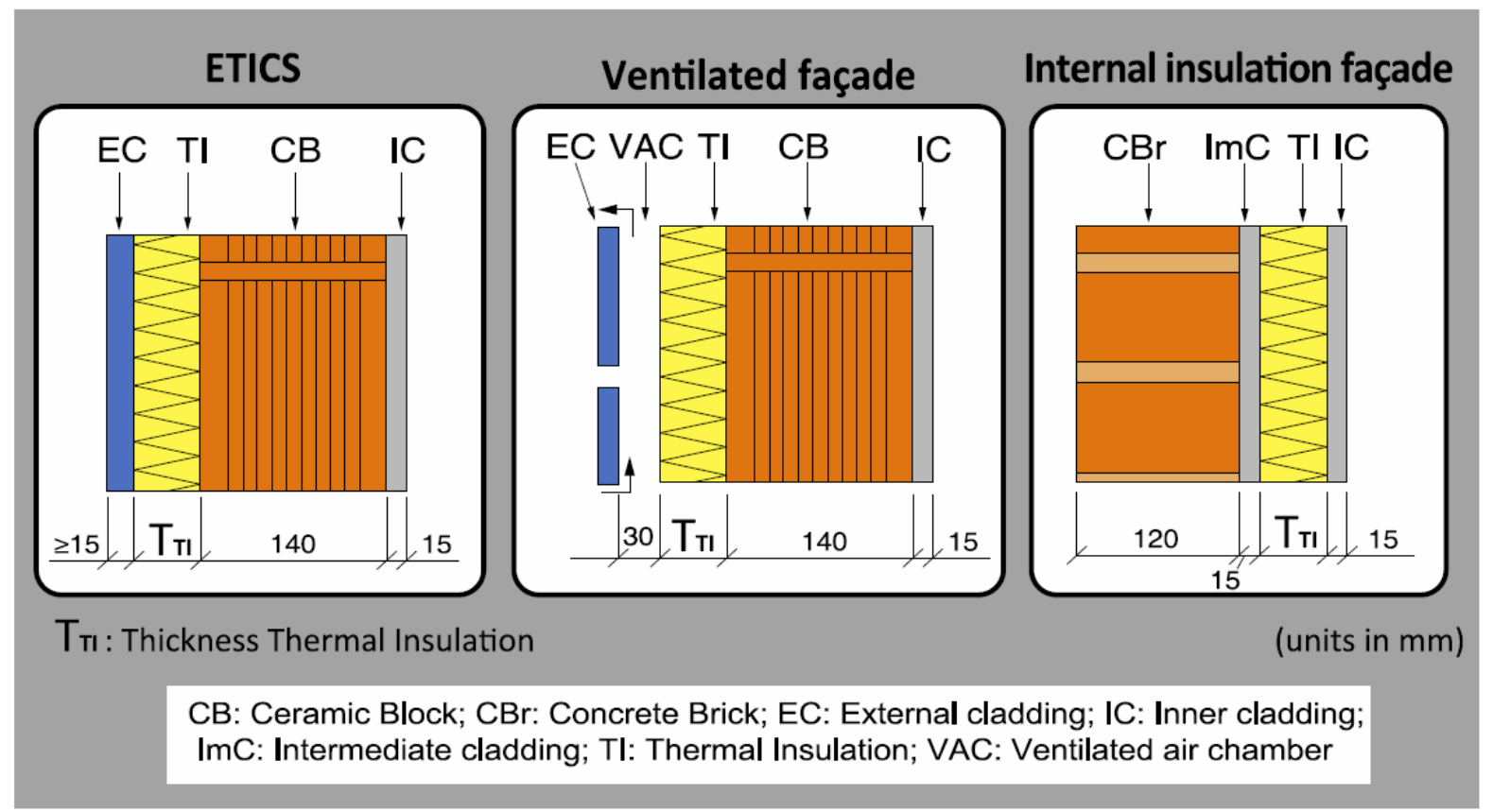

Figure 1. Constructive details of the studied façade systems (CSIC, 2008).

The choice of the realization of a ventilated façade, instead of any other, like a conventional façade, is due to the peculiarities and characteristics that it offers for the improvement of the enclosure of the building, such as its absorption and thermal transmittance [13].

When choosing the building materials, and above all, defining the thickness of their layers, we must take into account several factors, among which one of its most important ones is the climatology that the buildings will be exposed to during their useful life [14].

In Spain, the regulations [15] mark a differentiation by climatic zones according to the region and altitude with respect to the level of the sea, in addition to the climatic conditions at different times of the year, and their extreme temperatures during the winter and summer seasons. To carry out the life cycle study of the ventilated façade, the OpenLCA software has been used along with the Ecoinvent database [16-20]. 


\subsubsection{Ecoinvent database processes}

The Ecoinvent database provides different results depending on the location where the studio is made. In the initial versions of this database, the results were acquired in Switzerland $(\mathrm{CH})$, without discarding some processes for Europe (RER). With the evolution and development of the database, the countries of Canada (CA-QC) and Germany (DE) were incorporated. For the rest of the process where there was no specific location you select rest of the World (RoW) and Global (GLO).

In addition, when the life cycle Studio is performed, the same process presents variations according to distances between plants or quarries where the material used is produced, quantity of recycled material in the manufacturing process, among others. Therefore, Ecoinvent allows to introduce uncertainties associated to each process.

This uncertainty is divided into two stages. On the one hand, we find the uncertainty pertaining to the very nature of the process [18] and, on the other hand the uncertainty known as the pedigree matrix [19], which evaluates geographical and technological correlation, temporal correlation, reliability and integrity.

\subsubsection{Functional Unit}

In this study, the functional unit is the $\mathrm{m}^{2}$ of ventilated façade. For the realization of this type of buildings, you can consider the whole unit or just a part of it. In this case, to obtain a more detailed study of the flows produced by each constructive material and their environmental impacts, $1 \mathrm{~m}^{2}$ of enclosure is chosen [13,17,21-25].

\subsubsection{System Boundaries}

The system is divided into subsystems. We have considered the production subsystem, which includes the extraction, transport to plant and processing of each material; the construction subsystem, formed by the transport to the construction site, assembly and completion of the ventilated façade; the use and maintenance subsystem, including the energy consumed inside the building during the service life, and the end subsystem, with the demolition and waste disposal [26-30].

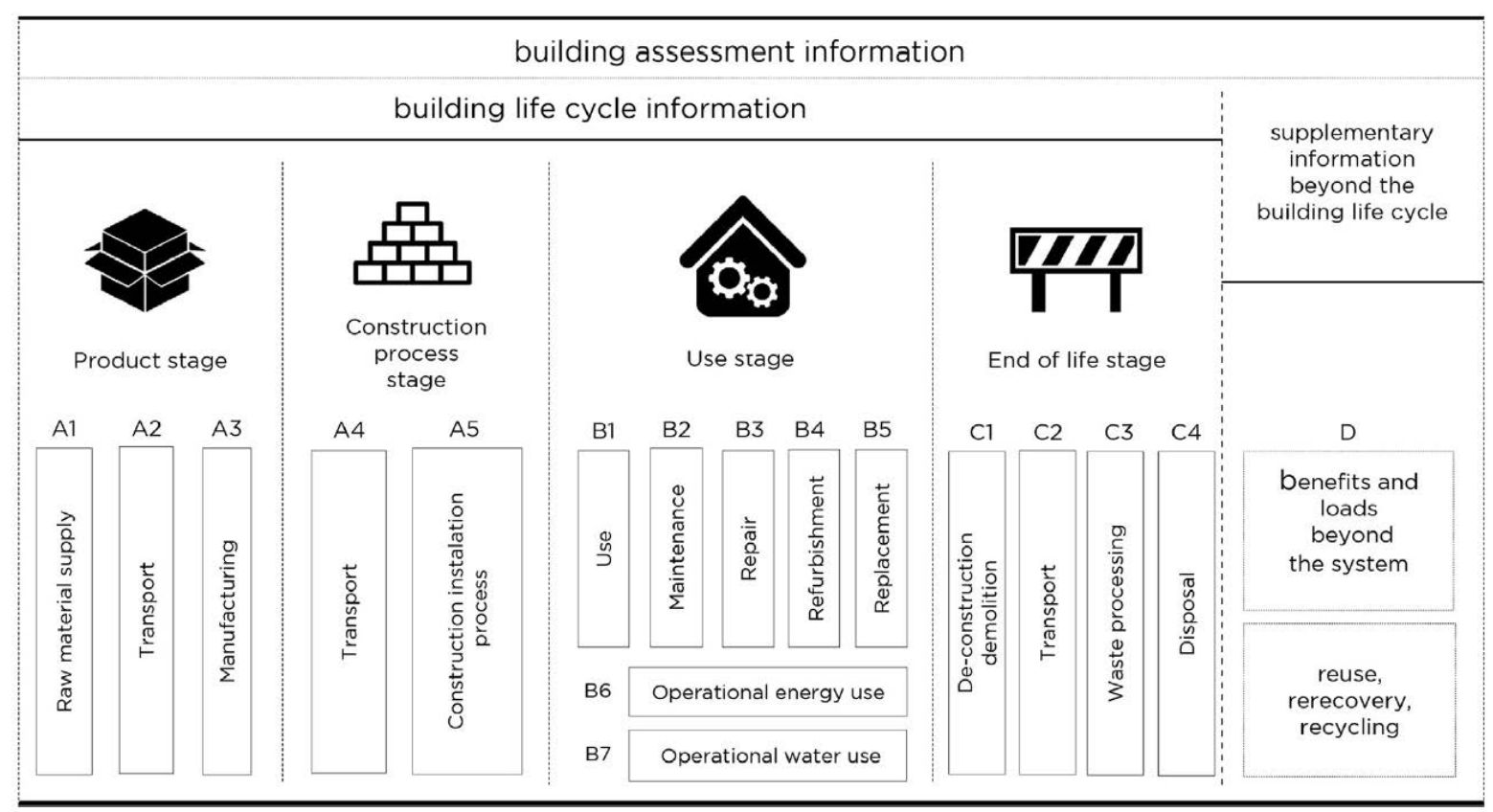

Figure 2. Scheme of the building assessment information modules based on 15978. [27]

\subsection{Case Study: A construction of ventilated façade in two countries}

Our object of study is the complete life cycle assessment of a square meter of ventilated façade with a constructive section formed by the materials and thicknesses described in Table 1. 
Table 1. Quantities and characteristics of the materials.

\begin{tabular}{|c|c|c|c|c|}
\cline { 2 - 5 } \multicolumn{1}{c|}{} & \begin{tabular}{c} 
Valencia \\
Thickness \\
\cline { 2 - 5 }
\end{tabular} & $\begin{array}{c}\text { Amount } \\
\left(\mathbf{m g} / \mathbf{1} \mathbf{m}^{\mathbf{2}}\right)\end{array}$ & $\begin{array}{c}\text { Thickness } \\
(\mathbf{m m})\end{array}$ & $\begin{array}{c}\text { Amount } \\
\left(\mathbf{k g} / \mathbf{1} \mathbf{m}^{\mathbf{2}}\right)\end{array}$ \\
\cline { 2 - 5 } & & 10 & $1000 \times 1000 \times 300$ & 10 \\
\hline External ceramic tile & $1000 \times 1000 \times 300$ & 6 & 80 & 12 \\
\hline Rock Wool & 40 & 8 & & 8 \\
\hline Aluminium fixation & & 90 & $230 \times 110 \times 70$ & 90 \\
\hline Light clay brick & $230 \times 110 \times 70$ & 19.5 & 15 & 19.5 \\
\hline Cement mortar & 15 & & & \\
\hline
\end{tabular}

When designing and building the envelope of any type of building, it is necessary to take into account the impacts to which it will be subjected; of external origin such as climatology, and those produced inside the building $[11,14]$.

In this case we analyze the same type of ventilated façade in two Spanish cities, Avila and Valencia. They are two completely different climatic zones, which are based on the height difference between that locality and the reference height of the capital of its province and are divided into 12 groups.

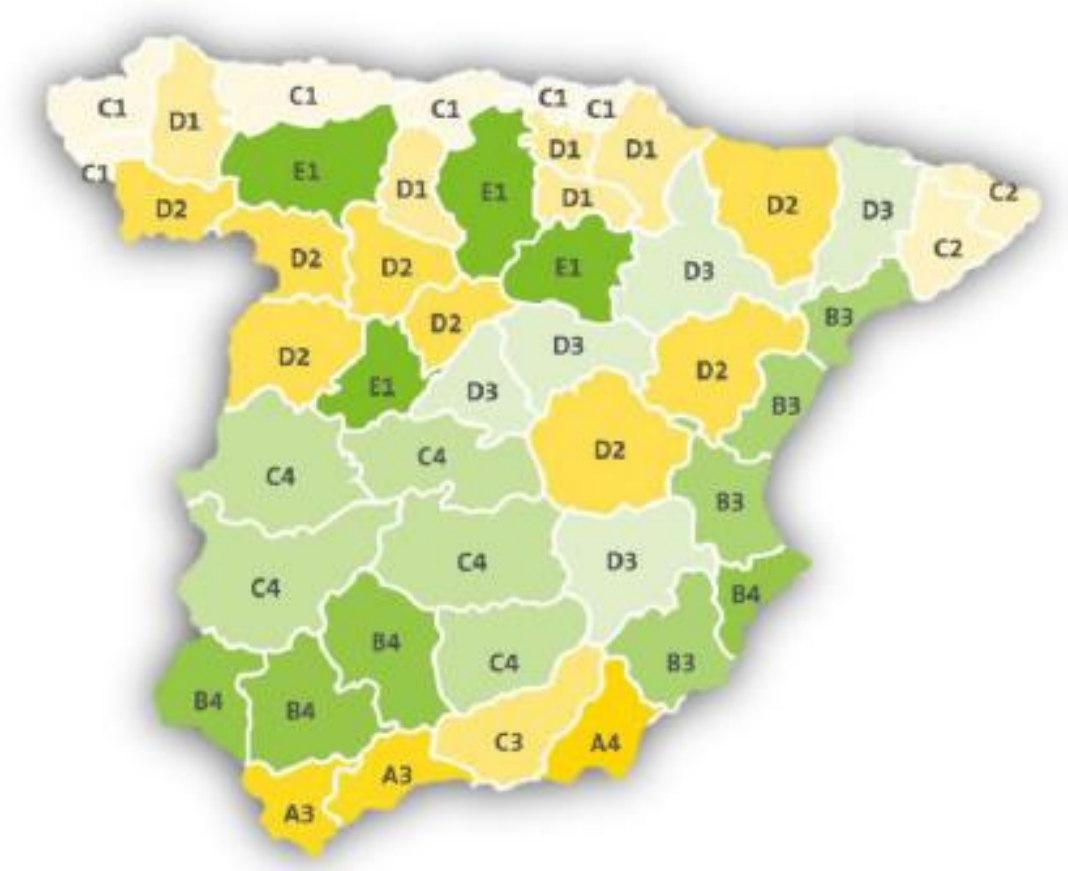

Figure 3. Climatic zones of all provincial capitals of Spain according to the CTE-DB-HE1 2017 [15].

Avila (E1) is a city with extreme temperatures in both summer and winter, unlike Valencia (B3) which has a much softer climate. These extreme temperatures imply the need to make a change in the constructive section of the ventilated façade.

Several studies have shown that modifying the thickness of the thermal insulator improves the response of the façade to any agent or external impacts [27, 32-34]. Therefore, when carrying out the study of the life cycle, two constructive sections are considered, one for Avila and another one for Valencia. The main difference between both sections lies in the thickness of the thermal insulator, which in our case study is about the mineral rock wool.

\subsubsection{Life Cycle Inventory Analysis}

As described above, different phases are taken into account in the life cycle analysis to study in detail which environmental impacts are produced in every phase. 
In the production phase, all the materials used in the construction of a square metre of ventilated façade are taken into account. The Ecoinvent database contains each one of the materials that form the constructive section of the façade.

For a greater and more accurate study of the impacts produced by the production of these materials, the distance from the extraction of the raw material to the plant where they are processed has been properly measured and considered, due to the impacts caused by the transportation of materials, mainly due to the emissions caused by the combustion engines of the trucks that have to carry the materials from their extraction site to their processing plants and the final construction site.

During the construction phase, the assembly and manipulation by the operators of the materials used in the construction of the ventilated façade is produced. This phase has taken into account the use of a mobile crane and the transport of each material already processed in a plant to the construction site.

The use and maintenance phase, in this case, has not been taken into account, because the energy produced inside the building by its users and activities, does not significantly contribute in the impacts caused by the square meter of the façade that is studied. This is due to the fact that a single square meter of façade would be responsible for an insignificant fraction of the total energy consumed by the entire building, therefore, to study its life cycle it should be discarded [27].

In the final phase, the demolition of the façade and the transport of its remains to the recycling and waste disposal plants has been analyzed, as well as the creation of a landfill for these materials.

\section{LIFE CYCLE ASSESSMENT RESULTS}

The results obtained from the Open LCA Software of the ventilated façade, have been divided into two groups, on the one hand, those obtained from the city of Valencia, and on the other hand, the city of Avila. These two groups of results have been compared to study the environmental impact in the production, construction, and final phases of the life cycle of the façade.

The uncertainty has been considered in each one of the phases through the pedigree matrix, in addition to conducting the Monte Carlo analysis with 1000 simulations. Therefore, a statistical analysis is made to study the distribution of the results obtained throughout the simulations, which are then compared according to their mean value and coefficient of variation. To facilitate the comparison of the results, the mean values have been displayed in the graphs, while their coefficient of variation is shown in the tables.

The objective is to quantify the impact that our ventilated façade produces. The result is a list of environmental indicators that depend on the evaluation system and method chosen. In this case, the $\mathrm{ReCiPe} 2008$ method has been used to assess the environmental impact, which combines the midpoint and endpoint approaches, based on the Eco 99 indicator [34]. The midpoint approach gives us the impact caused on basic categories such as climate change, human toxicity or water depletion. On the other hand, the endpoint approach groups these basic categories in three bigger clusters, composed by the damage caused to the resources, ecosystems and human health. Therefore, the endpoint approach provides results that are easier to interpret and understand, whereas the midpoint approach provides more detail, allowing a detailed analysis of certain specific emissions or impacts. Thus, combining both approaches, the total impact can be analyzed to draw conclusions.

\subsection{Midpoint approach}

With this approach, we obtain a great number of categories of impacts, providing a great level of detail. Every impact category has its own unit of measurement, for instance, the Global Warming Potential is quantified with the $\mathrm{kg}$ of $\mathrm{CO}_{2}$ emitted to the atmosphere while the Water Depletion uses the total volume of water required throughout the whole process. Thus, these categories are very useful to compare between alternative designs of methods, but it can be hard to determine which one has more contribution to the total impact caused throughout its life cycle. The impacts caused by a square meter of the ventilated façade in each climatic zone are displayed in Table 2, including their mean values and coefficients of variation. 
Table 2: Impacts caused by the ventilated façade. Mean value and coefficient of variation (cv).

Impact Category
Agricultural land occupation
Climate Change
Fossil depletion
Freshwater ecotoxicity
Freshwater eutrophication
Human toxicity
Ionising radiation
Marine ecotoxicity
Marine eutrophication
Metal depletion
Natural land transformation
Ozone depletion
Particulate matter formation
Photochemical oxidant formation
Terrestrial acidification
Terrestrial ecotoxicity
Urban land occupation
Water depletion

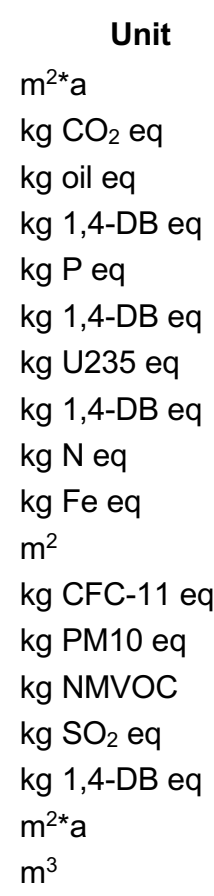

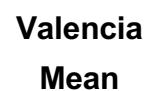

9.36114766

118.307565

32.6656477

1.41605638

0.02716613

30.6459122

7.3608334

1.28235004

0.05398696

6.0349623

0.03057513

1.2839E-05

0.36424223

0.46663837

0.5480577

0.20565172

1.30347537

334.172049

cv(\%)
$39 \%$
$11 \%$
$12 \%$
$12 \%$
$13 \%$
$15 \%$
$11 \%$
$12 \%$
$34 \%$
$24 \%$
$13 \%$
$12 \%$
$26 \%$
$11 \%$
$12 \%$
$61 \%$
$18 \%$
$10 \%$

Ávila

\begin{tabular}{cc}
\multicolumn{1}{c}{ Mean } & cv(\%) \\
9.86265972 & $36 \%$ \\
132.339269 & $12 \%$ \\
36.5040711 & $12 \%$ \\
1.53566185 & $12 \%$ \\
0.0305368 & $14 \%$ \\
34.4859547 & $14 \%$ \\
8.10650884 & $11 \%$ \\
1.39926817 & $12 \%$ \\
0.05638602 & $32 \%$ \\
6.5887318 & $20 \%$ \\
0.03547028 & $14 \%$ \\
$1.4147 \mathrm{E}-05$ & $12 \%$ \\
0.39511239 & $21 \%$ \\
0.51666851 & $13 \%$ \\
0.62818589 & $15 \%$ \\
0.20691243 & $59 \%$ \\
1.55108553 & $17 \%$ \\
356.622044 & $10 \%$
\end{tabular}

In this analysis, the comparison between the two cities studied is done with the average values of the impact because they are the most repercussion have. Table 3 shows the total impact in \% in every impact category, as it can be observed, the city of Avila causes around $50 \%$ more damage than Valencia in most impact categories: ALO, CC, FD, HT and IR. The ventilated façade located in Avila requires twice the amount of thermal insulation thickness than the one located in Valencia, therefore, being responsible for most of the variation in these impacts. On the other hand, we can observe that other impact categories like the PMF, TAC, TEC and ULO do not seem to be as affected by the increment in the thickness of the thermal insulation.

Table 3: Impacts caused by the ventilated façade.

$\quad$ Impact Category
Agricultural land occupation (ALO)
Climate Change (CH)
Fossil depletion (FD)
Freshwater ecotoxicity (FEC)
Freshwater eutrophication (FEU)
Human toxicity (HT)
lonising radiation (IR)
Marine ecotoxicity (MEC)
Marine eutrophication (MEU)
Metal depletion (MD)
Natural land transformation (NLT)
Ozone depletion (OD)
Particulate matter formation (PMF)
Photochemical oxidant formation (POF)
Terrestrial acidification (TA)
Terrestrial ecotoxicity (TEC)
Urban land occupation (ULO)
Water depletion (WD)

$\begin{array}{cc}\text { Valencia } & \text { Ávila } \\ 48.88 \% & 94.61 \% \\ 48.39 \% & 99.60 \% \\ 48.64 \% & 98.54 \% \\ 48.73 \% & 74.45 \% \\ 91.38 \% & 2.98 \% \\ 48.11 \% & 98.47 \% \\ 48.93 \% & 93.75 \% \\ 48.72 \% & 72.57 \% \\ 49.16 \% & 9.28 \% \\ 48.83 \% & 92.17 \% \\ 47.87 \% & 6.19 \% \\ 49.33 \% & 0.00 \% \\ 48.43 \% & 42.43 \% \\ 48.28 \% & 49.81 \% \\ 47.37 \% & 54.93 \% \\ 49.97 \% & 25.90 \% \\ 48.52 \% & 72.38 \% \\ 48.85 \% & 99.86 \%\end{array}$




\subsection{Endpoint approach}

With this approach, a global result is obtained in three categories of damage: resources, human health and ecosystems. Therefore, the results are easier to interpret and compare. The contribution of each phase of the life cycle assessment has been analyzed for every category.

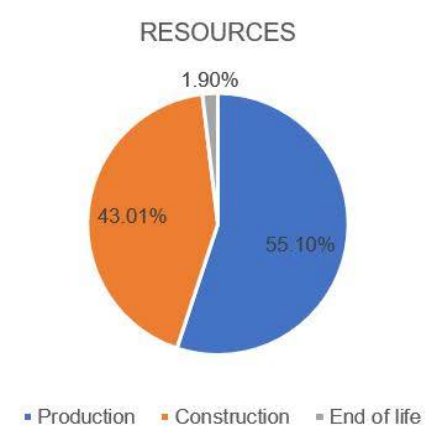

- Production = Construction = End of life
HUMAN HEALTH

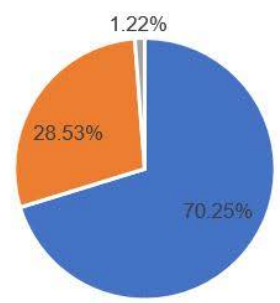

- Production = Construction = End of life
ECOSYSTEMS

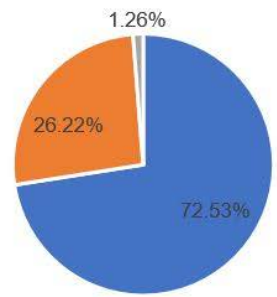

-Production - Construction "End of life

Figure 4. Impacts of Ávila city.

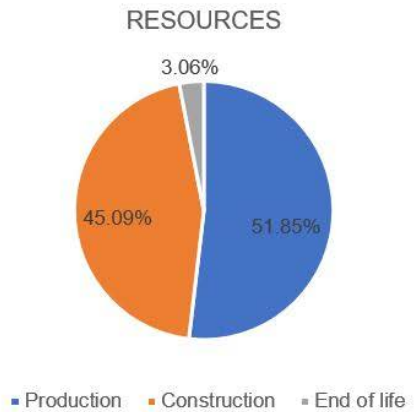

- Production - Construction = End of life
HUMAN HEALTH

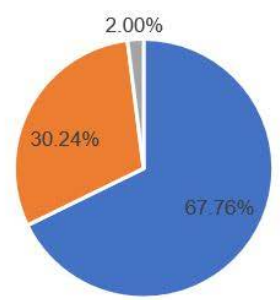

- Production - Construction = End of life
ECOSYSTEMS

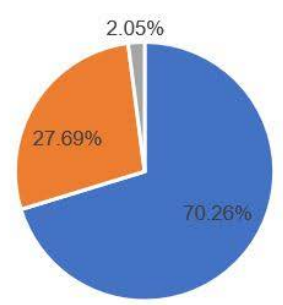

- Production - Construction = End of life

Figure 5. Impacts of Valencia city.

The results show that the most important phase and with the greatest impact of the two cities, is the production phase, surpassing in the three categories $50 \%$ of the total impact.

As mentioned above, the City of Avila presents a more extreme climatology, so its constructive section contains a greater thickness of rock wool. Therefore, if we analyze the results obtained, the production phase causes a $5 \%$ more damage to the resources; $3 \%$ more to human health; and $2 \%$ more damage to the ecosystem. On the other hand, if we look at the construction phase and end of life, we see that the city of Valencia has a higher \% in the three impacts analyzed. This means that the transport and the distances used have great repercussion and not only the variation of the thickness of the thermal insulator.

\section{CONCLUSIONS}

This paper described the methodology for the study of the life cycle of a ventilated façade. This study has been carried out in two Spanish cities with a completely different climatology in order to analyze the environmental impact of the three phases analyzed and to see if when making a change in the constructive section of the façade there is some Change in total impact. The results show that the total impact of the production, construction and end of life phases in Valencia and Ávila is similar. This leads us to the conclusion that due to the distances used in the transport of construction materials, the overall computation of the impact that occurs in both cities, only suffers slight variations. But on the other hand, the results obtained from the analysis of the midpoint, lead us to the conclusion that the increase in the thickness of the thermal insulation in the section of ventilated façade in Avila, also causes an increase in the different categories of impact (ALO, CC, FD, HT and IR). This increase is $50 \%$, which is the same as much increase in thickness of rock wool between one city and the other. In other categories of impact such as PMF, TAC, TEC and ULO, the difference between the two cities 
is less so that the thickness of the insulator does not affect. For a postgraduate student, this work gives them the necessary bases to be able to carry out a study of the life cycle. In addition, it serves to preamble future studies related to the constructive systems of ventilated façades.

\section{ACKNOWLEDGEMENTS}

The authors acknowledge the support for the Ministry of Economy and Company and FEDER funding (Project BIA2017-85098-R).

\section{REFERENCES}

[1] V. Yepes, E. Pellicer, and A. J. Ortega, "Designing a Benchmark Indicator for Managerial Competences in Construction at the Graduate Level," J. Prof. Issues Eng. Educ. Pract., vol. 138, no. 1, pp. 48-54, 2012.

[2] C. Torres-Machí, A. Carrión, V. Yepes, and E. Pellicer, "Employability of Graduate Students in Construction Management," J. Prof. Issues Eng. Educ. Pract., vol. 139, no. 2, pp. 163-170, 2013.

[3] E. Pellicer, L. A. Sierra, and V. Yepes, "Appraisal of infrastructure sustainability by graduate students using an active-learning method," J. Clean. Prod., vol. 113, pp. 884-896, 2016.

[4] T. García-Segura, V. Penadés-Plà, and V. Yepes, "Sustainable bridge design by metamodelassisted multi-objective optimization and decision-making under uncertainty," J. Clean. Prod., vol. 202, pp. 904-915, 2018.

[5] L. A. Sierra, V. Yepes, and E. Pellicer, "A review of multi-criteria assessment of the social sustainability of infrastructures," J. Clean. Prod., vol. 187, pp. 496-513, 2018.

[6] "Commission Europea" A. L. Comité, E. Y. Social, and E. Y. Al, "ES," 2012.

[7] "DIRECTIVE 2002/91/EC OF THE EUROPEAN PARLIAMENT AND OF THE COUNCIL of 16 December 2002 on the energy performance of buildings."

[8] "Directive 2010/31/EU of the European Parliament and of the Council of 19 May 2010 on the energy performance of buildings."

[9] M. Weißenberger, W. Jensch, and W. Lang, "The convergence of life cycle assessment and nearly zero-energy buildings: The case of Germany," Energy Build., vol. 76, pp. 551-557, Jun. 2014.

[10] L. F. Cabeza, L. Rincón, V. Vilariño, G. Pérez, and A. Castell, "Life cycle assessment (LCA) and life cycle energy analysis (LCEA) of buildings and the building sector: A review," Renew. Sustain. Energy Rev., vol. 29, pp. 394-416, 2014.

[11] J. Sierra-Pérez, J. Boschmonart-Rives, and X. Gabarrell, "Environmental assessment of façadebuilding systems and thermal insulation materials for different climatic conditions," J. Clean. Prod., vol. 113, no. 2016, pp. 102-113, 2016.

[12] V. Motuziene, A. Rogoža, V. Lapinskiene, and T. Vilutiene, "Construction solutions for energy efficient single-family house based on its life cycle multi-criteria analysis: A case study," J. Clean. Prod., vol. 112, pp. 532-541, 2016.

[13] C. Ingrao, F. Scrucca, C. Tricase, and F. Asdrubali, "A comparative Life Cycle Assessment of external wall-compositions for cleaner construction solutions in buildings," J. Clean. Prod., vol. 124, pp. 283-298, 2016.

[14] L. M. López-Ochoa, J. Las-Heras-Casas, L. M. López-González, and P. Olasolo-Alonso, "Environmental and energy impact of the EPBD in residential buildings in hot and temperate Mediterranean zones: The case of Spain," Energy, vol. 161, pp. 618-634, 2018.

[15] Ministerio de Fomento, "Documento Básico Ahorro de Energía DB-HE," pp. 1-68, 2017.

[16] J. J. Pons, V. Penadés-Plà, V. Yepes, and J. V. Martí, "Life cycle assessment of earth-retaining walls: An environmental comparison," J. Clean. Prod., vol. 192, pp. 411-420, 2018. 
[17] V. Penadés-Plà, T. García-Segura, J. V. Martí, and V. Yepes, "A review of multi-criteria decisionmaking methods applied to the sustainable bridge design," Sustainability, vol. 8, no. 12, p. 1295, 2016.

[18] L. A. Sierra, E. Pellicer, and V. Yepes, "Social Sustainability in the Lifecycle of Chilean Public Infrastructure," J. Constr. Eng. Manag., vol. 142, no. 5, p. 05015020, 2016.

[19] R. Frischknecht et al., "The ecoinvent database: Overview and methodological framework," Int. J. Life Cycle Assess., vol. 10, no. 1, pp. 3-9, 2005.

[20] A. Ciroth, S. Muller, B. Weidema, and P. Lesage, "Empirically based uncertainty factors for the pedigree matrix in ecoinvent," Int. J. Life Cycle Assess., vol. 21, no. 9, pp. 1338-1348, 2016.

[21] A. Carbonell, F. González-Vidosa, and V. Yepes, "Design of reinforced concrete road vaults by heuristic optimization," Adv. Eng. Softw., vol. 42, no. 4, pp. 151-159, 2011.

[22] V. Yepes, C. Torres-Machi, A. Chamorro, and E. Pellicer, "Optimal pavement maintenance programs based on a hybrid Greedy Randomized Adaptive Search Procedure Algorithm," J. Civ. Eng. Manag., vol. 22, no. 4, pp. 540-550, 2016.

[23] T. García-Segura, V. Yepes, J. Alcalá, and E. Pérez-López, "Hybrid harmony search for sustainable design of post-tensioned concrete box-girder pedestrian bridges," Eng. Struct., vol. 92, pp. 112-122, 2015.

[24] T. García-Segura and V. Yepes, "Multiobjective optimization of post-tensioned concrete box-girder road bridges considering cost, CO2 emissions, and safety," Eng. Struct., vol. 125, pp. 325-336, 2016.

[25] P. Zastrow, F. Molina-Moreno, T. García-Segura, J. V. Martí, and V. Yepes, "Life cycle assessment of cost-optimized buttress earth-retaining walls: A parametric study," J. Clean. Prod., vol. 140, pp. 1037-1048, 2017.

[26] B. Soust-Verdaguer, C. Llatas, and A. García-Martínez, "Simplification in life cycle assessment of single-family houses: A review of recent developments," Build. Environ., vol. 103, pp. 215-227, 2016.

[27] H. Monteiro and F. Freire, "Life-cycle assessment of a house with alternative exterior walls: Comparison of three impact assessment methods," Energy Build., vol. 47, pp. 572-583, 2012.

[28] Z. S. Zomorodian and M. Tahsildoost, "Energy and carbon analysis of double skin façades in the hot and dry climate," J. Clean. Prod., vol. 197, pp. 85-96, 2018.

[29] H. Hasheminasab, Y. Gholipour, M. Kharrazi, and D. Streimikiene, "Life cycle approach in sustainability assessment for petroleum refinery projects with fuzzy-AHP," Energy Environ., vol. 29, no. 7, pp. 1208-1223, 2018.

[30] A. F. Marique and B. Rossi, "Cradle-to-grave life-cycle assessment within the built environment: Comparison between the refurbishment and the complete reconstruction of an office building in Belgium,” J. Environ. Manage., vol. 224, pp. 396-405, 2018.

[31] B. E. 158:2011 EN 15978, "Sustainability of construction works-assessment of environmental performance of buildings-calculation method."

[32] L. F. Cabeza, A. Castell, M. Medrano, I. Martorell, G. Pérez, and I. Fernández, "Experimental study on the performance of insulation materials in Mediterranean construction," Energy Build., vol. 42, no. 5, pp. 630-636, 2010.

[33] B. P. Jelle, "Traditional, state-of-the-art and future thermal building insulation materials and solutions - Properties, requirements and possibilities," Energy Build., vol. 43, no. 10, pp. 25492563, 2011.

[34] B. Rodríguez-Soria, J. Domínguez-Hernández, J. M. Pérez-Bella, and J. J. del Coz-Díaz, "Review of international regulations governing the thermal insulation requirements of residential buildings and the harmonization of envelope energy loss," Renew. Sustain. Energy Rev., vol. 34, pp. 78-90, 2014. 